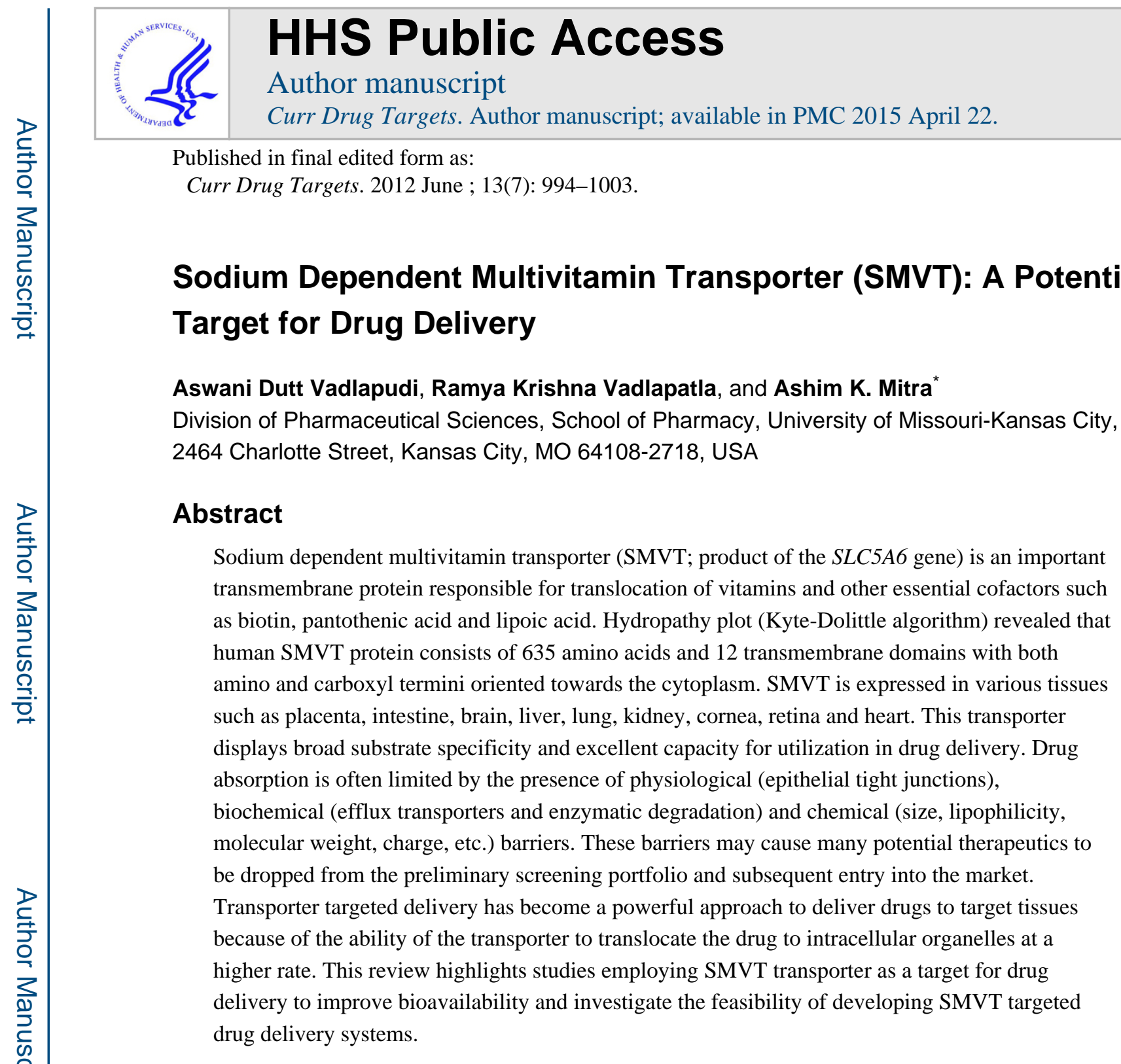

Keywords

SMVT; tissue distribution; substrate specificity; transporter targeted drug delivery

\title{
INTRODUCTION
}

Rapid technological developments in the field of drug discovery have led to the introduction of many new chemical entities into the market. Though these drug molecules may be therapeutically effective, delivery to the target site is still a challenging task mainly due to lack of optimal physicochemical properties and inability of molecules to overcome

\footnotetext{
(C) 2012 Bentham Science Publishers

'Address correspondence to this author at the University of Missouri Curators', Pharmaceutical Sciences, Vice-Provost for Interdisciplinary Research, University of Missouri - Kansas City, School of Pharmacy, 2464 Charlotte Street, Kansas City, MO 64108, USA; Tel: 816-235-1615; Fax: 816-235-5779; mitraa@umkc.edu, aswaniduttvadlapudi@mail.umkc.edu.

The authors declare no conflict of interest.
} 
physiological, biochemical and chemical barriers. These agents can be suitably formulated to overcome these barriers to a considerable extent. Inclusion of excipients/additives or polymers which transiently alter tight junctions between epithelial cells may be an approach to enhance permeation [1,2]. Moreover, membrane fluidizing agents and absorption/ penetration enhancers which are capable of lowering the permeability barrier thereby enhancing drug permeation have also been reported [3-5]. However, a more effective and viable approach would be to target a membrane transport system to facilitate drug absorption into cells. Transporter targeted delivery appears to be a promising approach in which either the active molecule or the colloidal carriers can be conjugated to a ligand which is a substrate for specific nutrient transporter. Specific substrates such as aminoacids (valine, serine, leucine etc), vitamins (biotin, riboflavin, ascorbic acid, folic acid) and glucose are translocated by specific transporters/receptors. Localization, structural elucidation, molecular and functional characterization of these membrane transport systems may aid in better design of targeted drug delivery systems. This review highlights sodium dependent multivitamin transporter (SMVT) as a highly promising target for drug delivery.

\section{BARRIERS TO DRUG DELIVERY}

Many active molecules are poorly absorbed through biological membranes due to low cell membrane partitioning properties. For any drug to be pharmacologically effective, it must reach the target cells (site of action) at optimal therapeutic concentrations over a required duration. Unfortunately, the presence of physiological, biochemical and chemical barriers can lead to heterogeneous distribution and accumulation of therapeutic molecules. Though several other factors need to be carefully considered, delivery of therapeutic drug concentrations at the desired site can only be achieved by overcoming these barriers.

\section{Physiological Barriers}

Drug absorption across an epithelium is mediated by a mechanism dependent on its physiochemical properties. Generally, molecules permeate through the membranes via paracellular or transcellular route. The paracellular pathway is defined as drug transport through the junctions or aqueous pores, between the cells. Drugs which are hydrophilic and cannot permeate through the cell membranes may utilize this mechanism for permeation. This pathway is mostly important for transport of ions, sugars, small hydrophilic and charged molecules.

The flux of a compound $\left(J_{p}\right)$ under sink conditions through the paracellular route is given by Eq. 1

$$
J_{p}=\frac{D_{p} * \varepsilon}{h_{p}} C_{d} \quad \text { Eq. } 1
$$

$D_{p}$ denotes diffusion coefficient through the intercellular spaces, $\in$ represents fraction of the paracellular route, $C_{d}$ is the donor drug concentration and $h_{p}$ is the effective pathlength of the paracellular route. 
However, tight junctions, adherens junctions and desmosomes serve as permeability barriers in epithelial and endothelial cells regulating the passage of ions and small molecules through the paracellular pathway [6-8].

The transcellular pathway is defined as transport through both apical and basolateral cellular (lipoidal) membranes, as well as through the internal aqueous environment of the cytoplasm. Since biological membranes are lipophilic, hydrophobic drugs can easily partition into the membrane. Similarly, the flux of a permeant $\left(J_{t}\right)$ under sink conditions through the transcellular route is given by Eq. 2

$$
J_{t}=\frac{(1-\varepsilon) D_{c} K_{c}}{h_{c}} C_{d} \quad \text { Eq. } 2
$$

$D_{c}$ and $K_{\mathrm{c}}$ represent diffusion and partition coefficients, respectively, and $h_{c}$ is the pathlength of the transcellular route.

\section{Biochemical Barriers}

Drug absorption may be limited by efflux and metabolism by enterocytes and hepatocytes respectively. Efflux transporters and metabolizing enzymes are known to regulate pharmacokinetic and pharmacodynamic interactions during drug absorption and metabolism [9-12]. Efflux transporters such as P-glycoprotein (P-gp), multi drug resistance associated protein (MRP) and breast cancer resistance protein (BCRP) as well as metabolizing enzymes i.e. cytochrome P450 system (CYP), esterases, peptidases, amidases and sulfotransferases may serve as biochemical barriers. Efflux transporters are proteins implicated in pumping out or extrusion of drug substrates and toxic molecules from within cells into the external environment. The key mechanism of efflux is dependent on energy derived from ATP hydrolysis. These membrane proteins are known to reduce intracellular drug concentration leading to subtherapeutic levels [13-15]. Multiple drug administrations to achieve optimal concentration may result in systemic toxicity along with emergence of drug resistance [1012]. Though these transporters are called as drug-resistant pumps, these proteins are expressed in many normal tissues mediating cellular transport of endogenous substrates [16].

\section{Chemical Barriers}

The chemical structure of an active molecule determines its solubility and permeability characteristics. Moreover, rate and extent of drug absorption depends on the concentration at the target site and permeability across the target cell membrane. Permeation via the paracellular route is determined by the physicochemical properties of the drug itself. Factors including the size, charge and hydrophilicity/lipophilicity are also the major factors influencing drug permeation. An alteration in the hydrophilicity of a drug molecule may alter the permeation pathway. For example, a shift in drug permeation from the paracellular to the transcellular route may be evident when the hydrophilicity of a drug molecule diminishes i.e., its lipophilicity ascends. 


\section{TRANSPORTER TARGETED DRUG DELIVERY}

Remarkable changes have been observed in the field of drug delivery over the past decade. In particular, a significant insight into various transporters present on the cell membrane opened a new window of opportunities [17-19]. Hydrophilic drug molecules which fail to efficiently permeate biological lipid membrane can be conveniently delivered via transporter targeted delivery systems [20-23]. Especially, compounds which serve as substrates for efflux transporters or metabolizing enzymes could be efficiently delivered via this approach $[10,11,24,25]$. Targeting nutrient transporters has emerged as an exciting strategy to enhance bioavailability of poorly permeating drugs. This approach typically involves conjugating the drug molecule or a colloidal carrier containing the active molecule to a ligand which serves as a substrate for a specific nutrient transporter in the cell membrane. Many transporters/receptors have been identified over the past decade. Amongst them, SMVT has been recently gaining importance due to its low affinity and high capacity along with wide substrate specificity.

\section{SODIUM DEPENDENT MULTIVITAMIN TRANSPORTER}

\section{Molecular Identity}

Sodium dependent multivitamin transporter (SMVT) is an electrogenic, highly sodium dependent carrier mediated system responsible for absorption of vitamins. It is a product of SLC5A6 gene, located on chromosome 2 and contains 17 exons. Topographical examination (hydrophobicity analysis) of rabbit intestinal SMVT (riSMVT), a $68.6 \mathrm{kDa}$ protein revealed the presence of 12 transmembrane domains (TMD) with both the N- and C- termini oriented towards the cytoplasm (intracellular region) (Fig. 1) [26, 27]. Despite significant new knowledge on the cell biology and regulation of the SMVT system, structure-function and structure-regulatory relationships are not fully known. However, cloning studies from many species including human, rabbit, mice and rat have delineated the molecular identity of SMVT $[27,28]$.

Role of the positively charged histidine (His) residues of SMVT in transclocating biotin was examined by site-directed mutagenesis approach. Nine His residues have been identified in the primary amino acid sequence of SMVT, of which seven residues are conserved across species (human, mouse, rat, and rabbit). The conserved His residues of human SMVT (hSMVT) polypeptide are located at positions 46, 54, 115, 125, 238, 254, and 533. His ${ }^{46}$ and $\mathrm{His}^{533}$ residues are expressed at the membrane-aqueous interface where as $\mathrm{His}^{54}$ and His ${ }^{125}$ residues are situated in the extracellular domains. $\mathrm{His}^{238}$ and $\mathrm{His}^{254}$ residues are in the large intracellular domain between sixth and seventh TMD and His ${ }^{115}$ is expressed on third TMD. Ghosal and Said investigated the role of His residues and the effect of chemical modification(s) on the functionality of the hSMVT system [29]. Mutations in the His ${ }^{115}$ and His $^{254}$ residues caused a significant reduction in carrier mediated biotin uptake indicating the functional expression of these two residues. Such mutative effect caused a significant decrease in the rate of maximal uptake (Vmax), but not the apparent binding affinity constant $(\mathrm{Km})$ of the carrier mediated process. This observation may be due to lowered number of hSMVT at the cell membrane without any change in affinity. 
Previous reports have suggested that hSMVT polypeptide contains four potential Nglycosylation sites ( $\mathrm{Asn}^{138}, \mathrm{Asn}^{489}, \mathrm{Asn}^{498}$ and $\mathrm{Asn}^{534}$ ) and two potential protein kinase $\mathrm{C}$ (PKC) phosphorylation sites ( $\mathrm{Ser}^{283}$ and $\mathrm{Thr}^{286}$ ) [26, 27]. N-glycosylation at Asn ${ }^{138}$ site was found to be unique to hSMVT while the other three potential N-glycosylation sites $\left(\mathrm{Asn}^{489}, \mathrm{Asn}^{498}\right.$ and $\left.\mathrm{Asn}^{534}\right)$ were conserved across human, mouse, rat and rabbit. Potential $\mathrm{N}$-glycosylation at $\mathrm{Asn}^{138}$ site is located in the extracellular domain between the third and fourth TMD of the hSMVT protein, while $\mathrm{Asn}^{489}$ and $\mathrm{Asn}^{498}$ sites are both located in the extracellular sequence between the eleventh and twelfth TMD. Asn ${ }^{534}$ site is situated within the twelfth TMD (Fig. 2). Effect of the putative N-glycosylation sites of the hSMVT polypeptide on the function and regulation of the carrier protein was investigated. Mutations in the Asn ${ }^{138}$ and $\mathrm{Asn}^{489}$ caused a significant reduction in the Vmax without a change in the apparent $\mathrm{Km}$ of the biotin uptake process. This observation may also be due to a reduction in the number and/or activity, but not affinity of the transport system. This study suggested that glycosylation of hSMVT is considered to be an important post translational modification affecting the mature transporter protein [30].

On the other hand, the two potential PKC-phosphorylation sites are predicted to be situated in the intracellular loop between the sixth and seventh TMD of the hSMVT protein (Fig. 2). Though Ser ${ }^{283}$ site is conserved across various species, $\mathrm{Thr}^{286}$ is conserved in human and rabbit but replaced by Ser in mouse and rat. Role of the potential PKC phosphorylation sites of hSMVT in mediating the phorbol myristate acetate (PMA) induced inhibition of biotin uptake was evaluated by mutating these sites. A significant decrease in PMA induced inhibition of biotin uptake was observed due to mutations in $\mathrm{Thr}^{286}$ sites, but not by $\mathrm{Ser}^{283}$ site. This effect was mediated only by a change in the functional activity of the hSMVT system itself, but not by changes in the expression of the hSMVT mRNA or total cellular level of the transporter protein [30].

Cysteine (Cys) residues appear to be involved in the regulation of SMVT [31, 32]. The hSMVT consists of 10 conserved Cys residues. Topological prediction analysis showed that Cys $^{68}$ and Cys ${ }^{144}$ of hSMVT protein are extracellular, Cys ${ }^{294}$ and Cys ${ }^{450}$ are cytoplasmic and $\mathrm{Cys}^{104}, \mathrm{Cys}^{186}, \mathrm{Cys}^{309}, \mathrm{Cys}^{358}, \mathrm{Cys}^{410}$ and $\mathrm{Cys}^{443}$ are expressed in the hydrophobic TMDs of the hSMVT polypeptide (Fig. 3). The exact role of a specific Cys residue in mediating the functional activity has not been delineated. A recent investigation addressed this issue using the molecular approach of site-directed mutagenesis [33]. Mutation on the $\mathrm{Cys}^{294}$ residue led to a significant reduction in biotin uptake. Replacement of $\mathrm{Cys}^{294}$ residue with a non-polar amino acid (alanine) or by another polar residue (serine) altered biotin uptake, suggesting that cysteine itself (not the polar or non-polar residue) is important for hSMVT function. Also a similar inhibition in biotin uptake was observed when Cys ${ }^{294}$ was mutated to the sulfur containing amino acid methionine, further confirming the importance of Cys residue. Results from these studies clearly suggest that the reduction in biotin uptake as a result of mutating Cys ${ }^{294}$ residue of hSMVT protein is presumably due to a decrease in the number of the hSMVT molecules at the cell membrane.

Overall, these findings suggest that hSMVT protein is glycosylated and this enzymatic process is important for its function. The significance of His ${ }^{115}$, His ${ }^{254}$ and Cys ${ }^{294}$ residues in the function and cell biology of hSMVT are clearly delineated. Moreover, the impact of 
putative PKC-phosphorylation site $\mathrm{Thr}^{286}$ of hSMVT in the PKC-mediated regulation of biotin uptake appear to be functionally important.

\section{Substrate Specificity and Transport Mechanism}

SMVT refers to a highly sodium dependent specific vitamin carrier system primarily responsible for translocation of biotin. Based on its sodium and substrate specificity, this transmembrane protein is referred as the sodium dependent multivitamin transporter. The concentration dependent accumulation of biotin uptake observed in the presence of an inwardly directed sodium $\left(\mathrm{Na}^{+}\right)$gradient suggests that fluxes on biotin and $\mathrm{Na}^{+}$ions are coupled with the activity of $\mathrm{Na}^{+}$-biotin co-transport mechanism [34]. The stoichiometric ratio of the biotin- $\mathrm{Na}^{+}$coupling may be examined by elevating the concentration of $\mathrm{Na}^{+}$in the incubation medium. The data was fitted into the Hill equation which provides an estimate of the number of $\mathrm{Na}^{+}$ions required for a substrate to interact with SMVT. Park et $a l$. has shown that each biotin molecule requires one sodium ion for its translocation across the cell membrane of brain microvessel endothelial cells (BMEC) [35]. Also, a similar coupling ratio of biotin to $\mathrm{Na}^{+}$was reported in human colonic epithelial (NCM460) cells suggesting that one $\mathrm{Na}^{+}$ion is required for transport of one biotin molecule. This study concluded that the transport process is electroneutral in nature [36]. These results are consistent with $\mathrm{Na}^{+}$-biotin cotransport (1:1 ratio) where biotin transport was evaluated in brush-border membrane vesicles from rat kidney [37]. Interestingly, transport of biotin and pantothenate mediated by rat SMVT seem to be electrogenic with a $\mathrm{Na}^{+}$: substrate coupling ratio of 2:1. This transport process appears to be associated with the transfer of one net positive charge across the membrane per transport cycle [38]. Kinetic analysis of $\mathrm{Na}^{+}$-biotin cotransport mechanism in the maternal-facing membrane of human placental epithelial cells revealed that $\mathrm{Na}^{+}$-biotin coupling ratio for the transporter is 2, i.e., about two $\mathrm{Na}$-ions are cotransported per biotin molecule across the cell membrane [34]. This effect may be due to inter-species or inter-tissue variability in different species which may alter transport mechanism by the carrier.

Vitamins are necessary for vital metabolic processes in all mammalian cells. Such cells involve intrinsic mechanisms for active accumulation of vitamins. The water-soluble vitamin, biotin is essential for normal cellular functions, growth and development. It serves as a cofactor for the carboxylases during fatty acid biosynthesis, gluconeogenesis and catabolism of several branched chain amino acids and odd-chain fatty acids. Deficiency of biotin leads to a range of clinical abnormalities such as neurologic disorders, growth retardation and skin abnormalities. Biotin can only be synthesized by bacteria, yeasts, molds, algae and a few plant species. Since humans and other mammals cannot synthesize, it must be supplemented from exogenous sources [39-42].

Structural and functional characterization of SMVT suggests that a single carrier mediated transport system probably mediates uptake of biotin (a coenzyme for carboxylation reaction), pantothenate (a component of coenzyme A) and lipoate (a component in oxidative decarboxylation of pyruvate and a-ketoglutarate) in the major absorptive tissues because these compounds share a degree of structural similarity $[43,44]$. The presence of SMVT responsible for the uptake of biotin, pantothenate and lipoate was first identified on human 
placenta [34, 45]. Subsequently, a second biotin-specific high affinity transporter was characterized on human keratinocytes and human peripheral blood mononuclear cells (PBMC) [46, 47]. Biotin transport appears to be coupled to electrochemical gradient of sodium but not to proton gradient. Since the pKa of biotin is in the range of $4-5$, a higher biotin uptake is observed at this $\mathrm{pH}$. This is due to larger fraction of unionized or neutral biotin component which permeates passively across the lipid bilayer of the cell membrane $[36,43,48]$.

Structure-function relationship between biotin and the uptake process can be better delineated by studying the kinetics in the presence of unlabeled biotin and by its structural analogs such as desthiobiotin. Kansara et al. have shown that biotin uptake is significantly inhibited in the presence of desthiobiotin in human retinoblastoma cell line (Y-79) [49]. The authors suggested that the thiophane component in the biotin structure plays an important role in binding to the transporter. Also results from this study suggested a requirement of keto group at the second position of the imidazole ring in biotin for the substrate to interact with SMVT. The tetrahydrothiophene ring which is absent in desthiobiotin does not appear to be a requirement for the transporter recognition because this analog is a potent inhibitor of biotin uptake. On the other hand, lipoic acid which is devoid of both the ring structure and the keto group is also a potent inhibitor of biotin uptake. Furthermore the effect of terminal carboxyl groups of the valeric acid side chain as well as the length of the side chain in influencing the interaction of biotin with the transporter has been investigated [34]. Biocytin and biotin methyl ester, where biotin was modified at the carboxyl group had no effect on the biotin uptake in Y-79 and rabbit primary corneal epithelial cells (rPCECs) [49, 50]. Both biotin methyl ester and biocytin lack a free carboxylic acid group in their structures. Interestingly, a significant concentration-dependent lowering in uptake was evident in the human retinal pigment epithelium (ARPE-19) cells [21]. Though these observations seem to be controversial, results suggest that a free valeric carboxylic group in biotin may or may not be a prerequisite for recognition and specific binding to SMVT [26, 51].

\section{Tissue Distribution}

Utilization of SMVT as a target for drug delivery depends both on the functional and molecular aspects of the transporter protein. Functional activity determines the ability of the transporter to translocate drug molecules, while the molecular evidence provides the adequate expression levels of the transporter suitable for drug delivery. However, the affinity and capacity of this transporter vary in different cells and tissues depending on their origin, nature of the cell line and disease condition as well (Table 1). SMVT is highly expressed in various tissues such as intestine [52-56], placenta [34, 45] liver [44, 52], cornea [50], kidney [43, 53, 56-58], retina [21, 59] and also in some carcinomatous tissues $[49,60]$. This expression pattern may enable SMVT as a target for drug delivery.

\section{UTILIZATION OF SMVT IN DRUG DELIVERY}

Biotin has been utilized in drug delivery and pharmaceutical biotechnology primarily due to its excellent affinity for avidin proteins. Cellular uptake of biotin appears to be mediated by SMVT, which is overexpressed in certain cancer cells. Expression of SMVT is usually higher than folate receptor in many lung, renal, colon, intestinal, breast and ovarian cancer 
cells [61]. Moreover, research focused on enhancing oral drug delivery demonstrated that biotin either covalently attached or surface modified on various constructs could enhance cellular uptake of various therapeutic molecules by active recognition by the transporter. Therefore, biotinylation of anticancer agents may augment tumor targeting.

Russell-Jones et al. have studied the potential of biotin as a targeting moiety in cancer chemotherapy [62]. Biotinylation of a fluorescently-labelled N-(2-hydroxypropyl) methacrylamide (HPMA) polymers enhanced tumor accumulation, following intravenous administration in mice. Consequently, the anticancer efficacy of HPMA-Doxorubicin conjugates against colon carcinoma xenografts is significantly enhanced due to biotin functionalization. Similar targeting approach was also investigated by employing polyethylene (PEG) prodrugs of camptothecin (CPT). CPT-PEG-biotin conjugates were synthesized and studied in vitro in A2780 sensitive and A2780/AD multi-drug resistant (MDR) human ovarian carcinoma cells. CPT-PEG-biotin conjugates showed an increase in CPT toxicity (5.2 times in sensitive and 2.1 times in multidrug-resistant cells) relative to non-biotinylated CPT-PEG conjugate. This enhanced cytotoxicity observed in the presence of biotinylated conjugate was due to site-specific uptake mediated by SMVT [60].

Recently, star-burst dendrimers have been investigated as a carrier platform for targeted drug delivery. Partially acetylated generation 5 (G5) polyamidoamine (PAMAM) dendrimers were designed and conjugated with biotin and fluorescein isothiocyanate (FITC) (Fig. 4). Results from this study indicate that dendrimer-biotin-FITC conjugate exhibits much higher cellular uptake into human cervix carcinoma (HeLa) cells compared to the conjugate devoid of biotin [63]. In another study, the effect of generation and the mechanism of cellular uptake of biotin-PAMAM (G4) dendrimers were examined in ovarian cancer (OVCAR-3) and human embryonic kidney (HEK 293T) cells. Uptake of biotinPAMAM was significantly higher in OVCAR-3 cells relative to HEK 293T cells suggesting their potential as nanocarriers in targeted drug delivery [64]. Subsequently, biotinylated PAMAM dendrimers loaded with cisplatin were evaluated for in vitro cytotoxic activity and cellular uptake of cisplatin in OVCAR-3, SKOV-3 (ovarian cancer), A2780 (wild-type) and CP70 (A2780/CP70, cisplatin- resistant) cells. Results from cytotoxicity studies showed that IC50 values of dendrimer-cisplatin complexes were significantly lower than cisplatin alone in OVCAR-3, SKOV-3 and CP70 cell lines [65].

SMVT has also been targeted to deliver large peptides orally by varying their absorptive transport pathways and improving intestinal permeability. The absorptive transport of novel peptidic inhibitors of the Tat protein of HIV-1, retro-inverso (R.I.-) K-Tat9 and R.I.K(biotin)-Tat9, were studied on Caco-2 and transfected Chinese Hamster Ovary (CHO) cells. Biotinylation of peptide significantly enhanced the absorptive permeability by elevating passive and carrier-mediated uptake by SMVT [51]. The $29 \mathrm{kDa}$ peptide-loaded bioconjugate (PEG:(R.I-Cys-K(biotin)-Tat9)8) and biotin-PEG-3400 are able to interact with human SMVT thereby accelerating cellular uptake and transport of these macromolecules. Absorptive transport of PEG-3350 across Caco-2 cell monolayers was not concentration-dependent and is probably mediated by passive diffusion. However, biotinPEG-3400 transport across Caco-2 cells follows concentration-dependent and saturable kinetics, suggesting a carrier mediated uptake process (Fig. 5). These results suggest that 
targeted PEG-based bioconjugates may improve cellular uptake and transport of larger as well as other small peptide therapeutic agents [66].

Thirty fold increase in the uptake of Tat9-C(biotin) with S-biotinylation of the cysteine residue was observed in Jurkat cells relative to unbiotinylated Tat9-C [67]. This enhanced effect may be due to stronger hydrophobic interactions with the plasma membrane as well as biotinylation, which further results in stronger inhibiton of transactivating process [68]. Wan et al. synthesized and investigated anti-HIV activities of peptides L-Tat9, R.I.CK-Tat9, R.I.CK (biotin)-Tat9 PEG in MT-2 cells, a HTLV-1-transformed human lymphoid cell line, infected with HIV-1 strain Vbu 3. R.I.CK-Tat9 $(E C 50=0.85 \mu \mathrm{M})$ exhibits stronger antiHIV activity relative to the L-form of Tat9 $(\mathrm{EC} 50=51.3 \mu \mathrm{M})$. Interestingly, conjugation of biotin to R.I.CK-Tat9 significantly enhances the peptide activity resulting in excellent antiHIV activity (EC50 $=0.018 \mu \mathrm{M})$. These results suggest that biotinylated R.I.CK-Tat9 is approximately 47 times more potent than R.I.CK-Tat9 [69].

Janoria et al. examined the role of SMVT on the uptake of biotin-ganciclovir (B-GCV) in both ARPE-19 cells and rabbit retina [21]. This study also delineates the intravitreal pharmacokinetics of GCV and B-GCV in unconscious New Zealand albino rabbits by an ocular microdialysis technique. B-GCV is recognized by SMVT transporter expressed on ARPE-19 cells and rabbit retina. The vitreal elimination half-lives of GCV (270 $\pm 15.7 \mathrm{~min})$ and Biotin-GCV (222 $\pm 40.5 \mathrm{~min})$ were not statistically different. However, the AUC of Biotin-GCV $\left(17.5 \pm 1.38 \mathrm{mg} * \mathrm{~min} * \mathrm{~mL}^{-1}\right)$ was significantly higher than GCV $(10.6 \pm 1.27$ $\left.\mathrm{mg} * \min * \mathrm{~mL}^{-1}\right)$. All the other parameters such as elimination rate constants, volume of distribution at steady state, clearance, mean residence time and even $\mathrm{C}_{\text {last }}$ did not significantly differ. Fig. (6) shows the sustained release of GCV following intravitreal administration of B-GCV. Vitreal concentration-time profile of B-GCV indicates regeneration of GCV at a concentration above the minimum inhibitory concentration (MIC) $(0.25-1.22 \mu \mathrm{g} / \mathrm{mL})$ [70]. This study concluded that intravitreal administration of B-GCV increases total exposure of GCV thereby leading to effective control of viral replication.

Luo et al. investigated the functional activity and molecular expression of SMVT in MDCKMDR1 cells (Madin-Darby canine kidney cells transfected with the human MDR1 gene) [43]. The authors have studied the transport characteristics of biotin and biotin-conjugated anti-HIV protease inhibitor, saquinavir (SQV). Biotin-saquinavir (B-SQV) prodrugs caused a significant diminution in the uptake and transport of $[3 \mathrm{H}]$ biotin, indicating the recognition of prodrug by SMVT. Since SQV is a well known substrate of P-glycoprotein (P-gp), this approach significantly lowered the efflux ratio of B-SQV in MDCK-MDR1 cells compared to SQV. This report suggests that B-SQV exhibits very low affinity towards P-gp compared to SQV. Another prodrug conjugate has been designed to control the release kinetics and cellular uptake of SQV at the target site and to enable site specificity. Conjugation of PEG to SQV produced a prodrug conjugate, SQV-Cys-PEG3400, which was less active.

Incorporation of biotin into the SQV-Cys-PEG3400 conjugate enhanced cell uptake of these conjugates since the hydrophobicity of biotin is known to promote cell membrane adhesion and enhanced cellular permeation. SQV-Cys-PEG3400-biotin $\left(\mathrm{ED}_{50}=125 \mathrm{nM}\right)$ generated 8fold greater antiviral activity than unbiotinylated conjugate, SQV-Cys-PEG3400 $\left(\mathrm{ED}_{50}=900 \mathrm{nM}\right)[71]$. 


\section{CONCLUSIONS AND FUTURE PERSPECTIVES}

Recent advances in molecular biology provide direct evidence of membrane transporter proteins, including molecular and functional characteristics. Transporter targeted delivery including either a prodrug approach or a drug delivery system or a combination of both seem to be a promising strategy for precise and efficient drug delivery, ultimately resulting in the enhancement of therapeutic efficacy. Transporter targeting strategy can not only facilitate enhanced drug permeation by overcoming physiological, biochemical and biological barriers, but also by enabling drug targeting at the intracellular level. The expression of SMVT under various physiological and pathological conditions needs to be critically evaluated to understand its regulation. Though there is sufficient evidence and encouraging data till date, additional studies are necessary to evaluate the drugs/drug delivery systems. The approach is to efficiently conjugate drugs to SMVT substrates without altering the ability of the carrier mediated transport system for efficient recognition and translocation. Nevertheless, further work is required to evaluate the utility of SMVT as a potential target for drug delivery. Tissue distribution, energetics and wide substrate specificity of SMVT offers a basis for its affinity and capacity of the transporter. Despite several advantages of targeting SMVT, a significant amount of research still needs to be conducted to investigate the feasibility of delivering therapeutics such as genes, si-RNA, antisense RNA, DNA, oligonucleotides, antibodies, peptides and proteins. Furthermore, the impact of pharmacokinetic properties on drug disposition is even more critical and remains a major factor. We anticipate that better knowledge and understanding of the role of SMVT in absorption and uptake processes would eventually contribute to better pharmacokinetic predictions in order to achieve site specific targeted delivery.

\section{ACKNOWLEDGEMENTS}

The authors would like to acknowledge NIH grants R01EY09171-16, R01EY010659-14 and R01GM 64320-04 for financial support.

\section{REFERENCES}

1. Dorkoosh FA, Setyaningsih D, Borchard G, Rafiee-Tehrani M, Verhoef JC, Junginger HE. Effects of superporous hydrogels on paracellular drug permeability and cytotoxicity studies in Caco- 2 cell monolayers. Int J Pharm. 2002; 241(1):35-45. [PubMed: 12086719]

2. Kotze AF, Luessen HL, de Leeuw BJ, de Boer AG, Verhoef JC, Junginger HE. Comparison of the effect of different chitosan salts and $\mathrm{N}$-trimethyl chitosan chloride on the permeability of intestinal epithelial cells (Caco-2). J Control Release. 1998; 51(1):35-46. [PubMed: 9685902]

3. Kuchimanchi KR, Gandhi MD, Sheta RR, et al. Intestinal absorption and biodistribution of cosalane and its amino acid conjugates: novel anti-HIV agents. Int J Pharm. 2002; 231(2):197-211. [PubMed: 11755272]

4. Tengamnuay P, Sahamethapat A, Sailasuta A, Mitra AK. Chitosans as nasal absorption enhancers of peptides: comparison between free amine chitosans and soluble salts. Int J Pharm. 2000; 197(1-2): 53-67. [PubMed: 10704793]

5. Shao Z, Li Y, Chermak T, Mitra AK. Cyclodextrins as mucosal absorption promoters of insulin. II. Effects of beta-cyclodextrin derivatives on alpha-chymotryptic degradation and enteral absorption of insulin in rats. Pharm Res. 1994; 11(8):1174-1179. [PubMed: 7971720]

6. Ward PD, Tippin TK, Thakker DR. Enhancing paracellular permeability by modulating epithelial tight junctions. Pharm Sci Technolo Today. 2000; 3(10):346-358. [PubMed: 11050459] 
7. Anderson JM, Van Itallie CM. Tight junctions and the molecular basis for regulation of paracellular permeability. Am J Physiol. 1995; 269(4 Pt 1):G467-G475. [PubMed: 7485497]

8. Powell DW. Barrier function of epithelia. Am J Physiol. 1981; 241(4):G275-G288. [PubMed: 7032321]

9. Pal D, Kwatra D, Minocha M, Paturi DK, Budda B, Mitra AK. Efflux transporters- and cytochrome P-450-mediated interactions between drugs of abuse and antiretrovirals. Life Sci. 2011; 88(21-22): 959-971. [PubMed: 20932495]

10. Kwatra D, Vadlapatla RK, Vadlapudi AD, Pal D, Mitra AK. Interaction of gatifloxacin with efflux transporters: a possible mechanism for drug resistance. Int J Pharm. 2010; 395(1-2):114-121. [PubMed: 20573570]

11. Pal D, Mitra AK. MDR- and CYP3A4-mediated drug-drug interactions. J Neuroimmune Pharmacol. 2006; 1(3):323-339. [PubMed: 18040809]

12. Pal D, Mitra AK. MDR- and CYP3A4-mediated drug-herbal interactions. Life Sci. 2006; 78(18): 2131-2145. [PubMed: 16442130]

13. McKeegan KS, Borges-Walmsley MI, Walmsley AR. The structure and function of drug pumps: an update. Trends Microbiol. 2003; 11(1):21-29. [PubMed: 12526851]

14. Saier MH Jr, Paulsen IT. Phylogeny of multidrug transporters. Semin Cell Dev Biol. 2001; 12(3): 205-213. [PubMed: 11428913]

15. Putman M, van Veen HW, Konings WN. Molecular properties of bacterial multidrug transporters. Microbiol Mol Biol Rev. 2000; 64(4):672-693. [PubMed: 11104814]

16. Gottesman MM, Fojo T, Bates SE. Multidrug resistance in cancer: role of ATP-dependent transporters. Nat Rev Cancer. 2002; 2(1):48-58. [PubMed: 11902585]

17. Gaudana R, Ananthula HK, Parenky A, Mitra AK. Ocular drug delivery. AAPS J. 2010; 12(3): 348-360. [PubMed: 20437123]

18. Gaudana R, Jwala J, Boddu SH, Mitra AK. Recent perspectives in ocular drug delivery. Pharm Res. 2009; 26(5):1197-1216. [PubMed: 18758924]

19. Yang C, Tirucherai GS, Mitra AK. Prodrug based optimal drug delivery via membrane transporter/ receptor. Expert Opin Biol Ther. 2001; 1(2):159-175. [PubMed: 11727527]

20. Vadlapudi AD, Vadlapatla RK, Mitra AK. Current and emerging antivirals for the treatment of cytomegalovirus (CMV) retinitis: an update on recent patents. Recent Pat Antiinfect Drug Discov. 2011 in press.

21. Janoria KG, Boddu SH, Wang Z, et al. Vitreal pharmacokinetics of biotinylated ganciclovir: role of sodium-dependent multivitamin transporter expressed on retina. J Ocul Pharmacol Ther. 2009; 25(1):39-49. [PubMed: 19232011]

22. Talluri RS, Samanta SK, Gaudana R, Mitra AK. Synthesis, metabolism and cellular permeability of enzymatically stable dipeptide prodrugs of acyclovir. Int J Pharm. 2008; 361(1-2):118-124. [PubMed: 18573320]

23. Anand BS, Dey S, Mitra AK. Current prodrug strategies via membrane transporters/receptors. Expert Opin Biol Ther. 2002; 2(6):607-620. [PubMed: 12171505]

24. Vadlapatla RK, Vadlapudi AD, Kwatra D, Pal D, Mitra AK. Differential effect of P-gp and MRP2 on cellular translocation of gemifloxacin. Int J Pharm. 2011; 420(1):26-33. [PubMed: 21864659]

25. Luo S, Wang Z, Patel M, et al. Targeting SVCT for enhanced drug absorption: synthesis and in vitro evaluation of a novel vitamin C conjugated prodrug of saquinavir. Int J Pharm. 2011; 414(12):77-85. [PubMed: 21571053]

26. Prasad PD, Wang H, Huang W, et al. Molecular and functional characterization of the intestinal Na +-dependent multivitamin transporter. Arch Biochem Biophys. 1999; 366(1):95-106. [PubMed: 10334869]

27. Wang H, Huang W, Fei YJ, et al. Human placental Na+-dependent multivitamin transporter. Cloning, functional expression, gene structure, and chromosomal localization. J Biol Chem. 1999; 274(21):14875-14883. [PubMed: 10329687]

28. Chatterjee NS, Kumar CK, Ortiz A, Rubin SA, Said HM. Molecular mechanism of the intestinal biotin transport process. Am J Physiol. 1999; 277(4 Pt 1):C605-C613. [PubMed: 10516089] 
29. Ghosal A, Said HM. Structure-function activity of the human sodium-dependent multivitamin transporter: role of His ${ }^{1} 15$ and His(2). Am J Physiol Cell Physiol. 2011; 300(1):C97-C104. [PubMed: 20962270]

30. Ghosal A, Subramanian VS, Said HM. Role of the putative N-glycosylation and PKCphosphorylation sites of the human sodium-dependent multivitamin transporter (hSMVT) in function and regulation. Biochim Biophys Acta. 2011; 1808(8):2073-2080. [PubMed: 21570947]

31. Said HM, Ma TY, Kamanna VS. Uptake of biotin by human hepatoma cell line, Hep G2: a carriermediated process similar to that of normal liver. J Cell Physiol. 1994; 161(3):483-489. [PubMed: 7525615]

32. Said HM, Mohammadkhani R. Involvement of histidine residues and sulfhydryl groups in the function of the biotin transport carrier of rabbit intestinal brush-border membrane. Biochim Biophys Acta. 1992; 1107(2):238-244. [PubMed: 1504068]

33. Ghosal A, Said HM. Cys(294) is essential for the function of the human sodium-dependent multivitamin transporter. Biochim Biophys Acta. 2011; 1818(1):97-102. [PubMed: 22015582]

34. Grass1 SM. Human placental brush-border membrane Na(+)-biotin cotransport. J Biol Chem. 1992; 267(25):17760-17765. [PubMed: 1381353]

35. Park S, Sinko PJ. The blood-brain barrier sodium-dependent multivitamin transporter: a molecular functional in vitro-in situ correlation. Drug Metab Dispos. 2005; 33(10):1547-1554. [PubMed: 16033951]

36. Said HM, Ortiz A, McCloud E, Dyer D, Moyer MP, Rubin S. Biotin uptake by human colonic epithelial NCM460 cells: a carrier-mediated process shared with pantothenic acid. Am J Physiol. 1998; 275(5 Pt 1):C1365-C1371. [PubMed: 9814986]

37. Baur B, Wick H, Baumgartner ER. Na(+)-dependent biotin transport into brush-border membrane vesicles from rat kidney. Am J Physiol. 1990; 258(4 Pt 2):F840-F847. [PubMed: 2330980]

38. Prasad PD, Srinivas SR, Wang H, Leibach FH, Devoe LD, Ganapathy V. Electrogenic nature of rat sodium-dependent multivitamin transport. Biochem Biophys Res Commun. 2000; 270(3):836840. [PubMed: 10772912]

39. Zempleni J, Mock DM. Marginal biotin deficiency is teratogenic. Proc Soc Exp Biol Med. 2000; 223(1):14-21. [PubMed: 10632957]

40. Dakshinamurti K, Chauhan J. Regulation of biotin enzymes. Annu Rev Nutr. 1988; 8:211-233. [PubMed: 2904822]

41. Sweetman L, Nyhan WL. Inheritable biotin-treatable disorders and associated phenomena. Annu Rev Nutr. 1986; 6:317-343. [PubMed: 3089241]

42. Bonjour, JP. Biotin. In: Machlin, LJ., editor. Handbook of Vitamins; Nutritional Biochemical and Clinical Aspects. New York: Dekker; 1984. p. 403-435.

43. Luo S, Kansara VS, Zhu X, Mandava NK, Pal D, Mitra AK. Functional characterization of sodium-dependent multivitamin transporter in MDCK-MDR1 cells and its utilization as a target for drug delivery. Mol Pharm. 2006; 3(3):329-339. [PubMed: 16749865]

44. Prasad PD, Ganapathy V. Structure and function of mammalian sodium-dependent multivitamin transporter. Curr Opin Clin Nutr Metab Care. 2000; 3(4):263-266. [PubMed: 10929671]

45. Grassl SM. Human placental brush-border membrane $\mathrm{Na}(+)$-pantothenate cotransport. J Biol Chem. 1992; 267(32):22902-22906. [PubMed: 1429639]

46. Grafe F, Wohlrab W, Neubert RH, Brandsch M. Transport of biotin in human keratinocytes. J Invest Dermatol. 2003; 120(3):428-433. [PubMed: 12603856]

47. Zempleni J, Mock DM. Uptake and metabolism of biotin by human peripheral blood mononuclear cells. Am J Physiol. 1998; 275(2 Pt 1):C382-C388. [PubMed: 9688592]

48. Said HM, Redha R, Nylander W. Biotin transport in the human intestine: site of maximum transport and effect of pH. Gastroenterology. 1988; 95(5):1312-1317. [PubMed: 3169497]

49. Kansara V, Luo S, Balasubrahmanyam B, Pal D, Mitra AK. Biotin uptake and cellular translocation in human derived retinoblastoma cell line (Y-79): a role of hSMVT system. Int J Pharm. 2006; 312(1-2):43-52. [PubMed: 16459033]

50. Janoria KG, Hariharan S, Paturi D, Pal D, Mitra AK. Biotin uptake by rabbit corneal epithelial cells: role of sodium-dependent multivitamin transporter (SMVT). Curr Eye Res. 2006; 31(10): 797-809. [PubMed: 17038304] 
51. Ramanathan S, Pooyan S, Stein S, et al. Targeting the sodium-dependent multivitamin transporter (SMVT) for improving the oral absorption properties of a retro-inverso Tat nonapeptide. Pharm Res. 2001; 18(7):950-956. [PubMed: 11496954]

52. Balamurugan K, Ortiz A, Said HM. Biotin uptake by human intestinal and liver epithelial cells: role of the SMVT system. Am J Physiol Gastrointest Liver Physiol. 2003; 285(1):G73-G77. [PubMed: 12646417]

53. Nabokina SM, Subramanian VS, Said HM. Comparative analysis of ontogenic changes in renal and intestinal biotin transport in the rat. Am J Physiol Renal Physiol. 2003; 284(4):F737-F742. [PubMed: 12620923]

54. Chatterjee NS, Rubin SA, Said HM. Molecular characterization of the 5 ' regulatory region of rat sodium-dependent multivitamin transporter gene. Am J Physiol Cell Physiol. 2001; 280(3):C548C555. [PubMed: 11171574]

55. Said HM. Cellular uptake of biotin: mechanisms and regulation. J Nutr. 1999; 129 Suppl(2S): 490S-493S. [PubMed: 10064315]

56. Said HM, Redha R, Nylander W. A carrier-mediated, Na+ gradient-dependent transport for biotin in human intestinal brush-border membrane vesicles. Am J Physiol. 1987; 253(5 Pt 1):G631G636. [PubMed: 3120597]

57. Balamurugan K, Vaziri ND, Said HM. Biotin uptake by human proximal tubular epithelial cells: cellular and molecular aspects. Am J Physiol Renal Physiol. 2005; 288(4):F823-F831. [PubMed: 15561972]

58. Baur B, Baumgartner ER. Na(+)-dependent biotin transport into brush-border membrane vesicles from human kidney cortex. Pflugers Arch. 1993; 422(5):499-505. [PubMed: 8474852]

59. Ohkura Y, Akanuma S, Tachikawa M, Hosoya K. Blood-to-retina transport of biotin via Na+dependent multivitamin transporter (SMVT) at the inner blood-retinal barrier. Exp Eye Res. 2010; 91(3):387-392. [PubMed: 20599968]

60. Minko T, Paranjpe PV, Qiu B, et al. Enhancing the anticancer efficacy of camptothecin using biotinylated poly(ethylene glycol) conjugates in sensitive and multidrug-resistant human ovarian carcinoma cells. Cancer Chemother Pharmacol. 2002; 50(2):143-150. [PubMed: 12172980]

61. Bildstein L, Dubernet C, Couvreur P. Prodrug-based intracellular delivery of anticancer agents. Adv Drug Deliv Rev. 2011; 63(1-2):3-23. [PubMed: 21237228]

62. Russell-Jones G, McTavish K, McEwan J, Rice J, Nowotnik D. Vitamin-mediated targeting as a potential mechanism to increase drug uptake by tumours. J Inorg Biochem. 2004; 98(10):16251633. [PubMed: 15458825]

63. Yang W, Cheng Y, Xu T, Wang X, Wen LP. Targeting cancer cells with biotin-dendrimer conjugates. Eur J Med Chem. 2009; 44(2):862-868. [PubMed: 18550227]

64. Yellepeddi VK, Kumar A, Palakurthi S. Biotinylated poly(amido)amine (PAMAM) dendrimers as carriers for drug delivery to ovarian cancer cells in vitro. Anticancer Res. 2009; 29(8):2933-2943. [PubMed: 19661298]

65. Yellepeddi VK, Kumar A, Maher DM, Chauhan SC, Vangara KK, Palakurthi S. Biotinylated PAMAM dendrimers for intracellular delivery of cisplatin to ovarian cancer: role of SMVT. Anticancer Res. 2011; 31(3):897-906. [PubMed: 21498711]

66. Ramanathan S, Qiu B, Pooyan S, et al. Targeted PEG-based bioconjugates enhance the cellular uptake and transport of a HIV-1 TAT nonapeptide. J Control Release. 2001; 77(3):199-212. [PubMed: 11733088]

67. Choudhury I, Wang J, Rabson AB, Stein S, Pooyan S, Leibowitz MJ. Inhibition of HIV-1 replication by a Tat RNA-binding domain peptide analog. J Acquir Immune Defic Syndr Hum Retrovirol. 1998; 17(2):104-111. [PubMed: 9473010]

68. Chen LL, Frankel AD, Harder JL, Fawell S, Barsoum J, Pepinsky B. Increased cellular uptake of the human immunodeficiency virus-1 Tat protein after modification with biotin. Anal Biochem. 1995; 227(1):168-175. [PubMed: 7668378]

69. Wan L, Zhang X, Gunaseelan S, et al. Novel multi-component nanopharmaceuticals derived from poly(ethylene) glycol, retroinverso-Tat nonapeptide and saquinavir demonstrate combined antiHIV effects. AIDS Res Ther. 2006; 3:12. [PubMed: 16635263] 
70. Macha S, Mitra AK. Ocular disposition of ganciclovir and its monoester prodrugs following intravitreal administration using microdialysis. Drug Metab Dispos. 2002; 30(6):670-675. [PubMed: 12019194]

71. Gunaseelan S, Debrah O, Wan L, et al. Synthesis of poly(ethylene glycol)-based saquinavir prodrug conjugates and assessment of release and anti-HIV-1 bioactivity using a novel protease inhibition assay. Bioconjug Chem. 2004; 15(6):1322-1333. [PubMed: 15546199]

72. Said HM, Hoefs J, Mohammadkhani R, Horne DW. Biotin transport in human liver basolateral membrane vesicles: a carrier-mediated, $\mathrm{Na}+$ gradient-dependent process. Gastroenterology. 1992; 102(6):2120-2125. [PubMed: 1587433]

73. Ma TY, Dyer DL, Said HM. Human intestinal cell line Caco-2: a useful model for studying cellular and molecular regulation of biotin uptake. Biochim Biophys Acta. 1994; 1189(1):81-88. [PubMed: 7508263] 


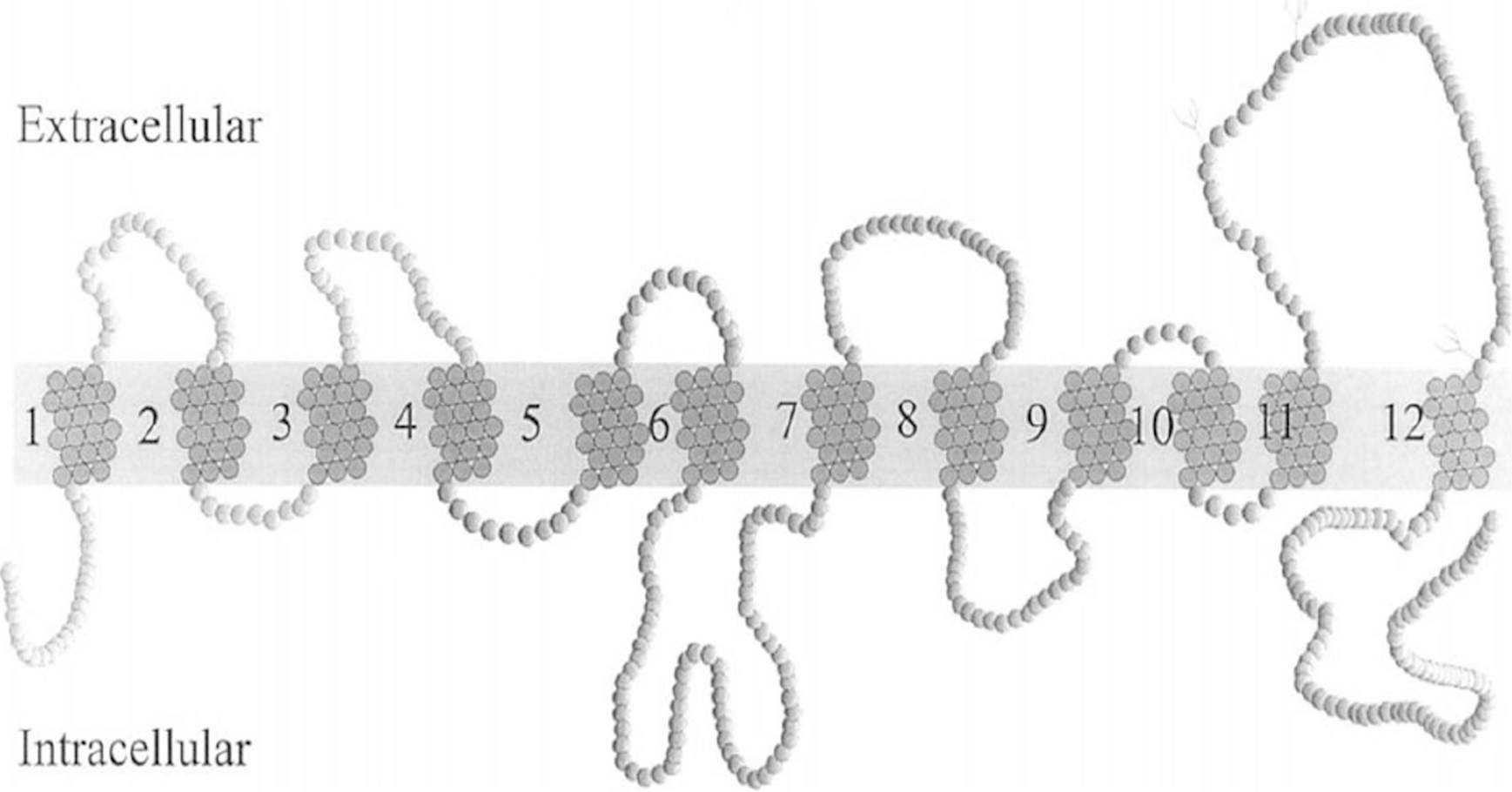

Fig. (1).

Model of the membrane topology of riSMVT deduced from the Kyte-Doolittle hydropathy plot. The hSMVT polypeptide is predicted to have 12 TMD. Reproduced with permission from Ref [26]. 
A

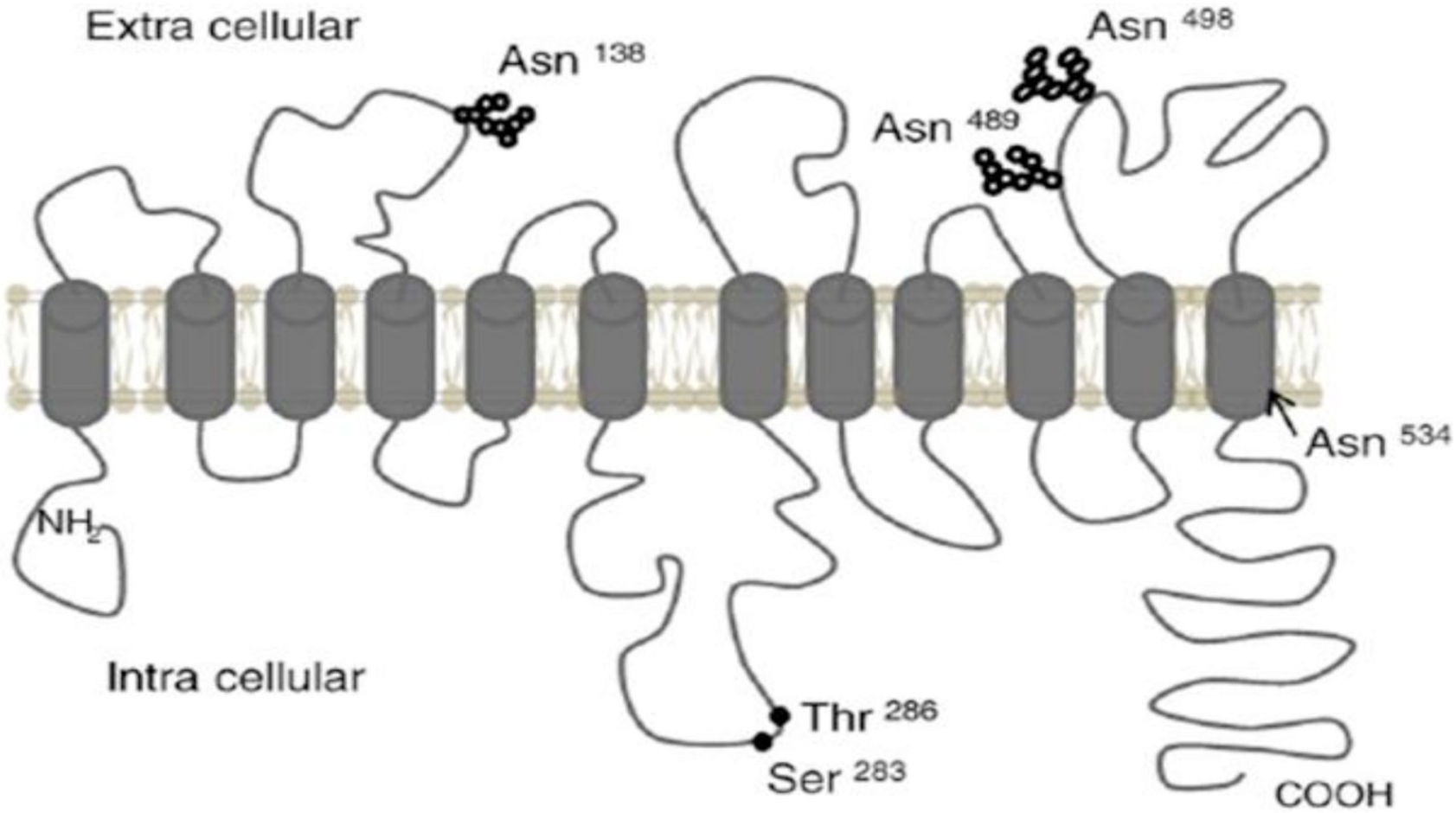

Fig. (2).

Predicted membrane topology of hSMVT protein to have four putative N-glycosylation motifs (Asn ${ }^{138}, \mathrm{Asn}^{489}, \mathrm{Asn}^{498}$ and Asn ${ }^{534}$ ) and two potential PKC-phosphorylation sites $\left(\mathrm{Ser}^{283}\right.$ and $\left.\mathrm{Thr}^{286}\right)$. Reproduced with permission from Ref [30]. 
Extracellular

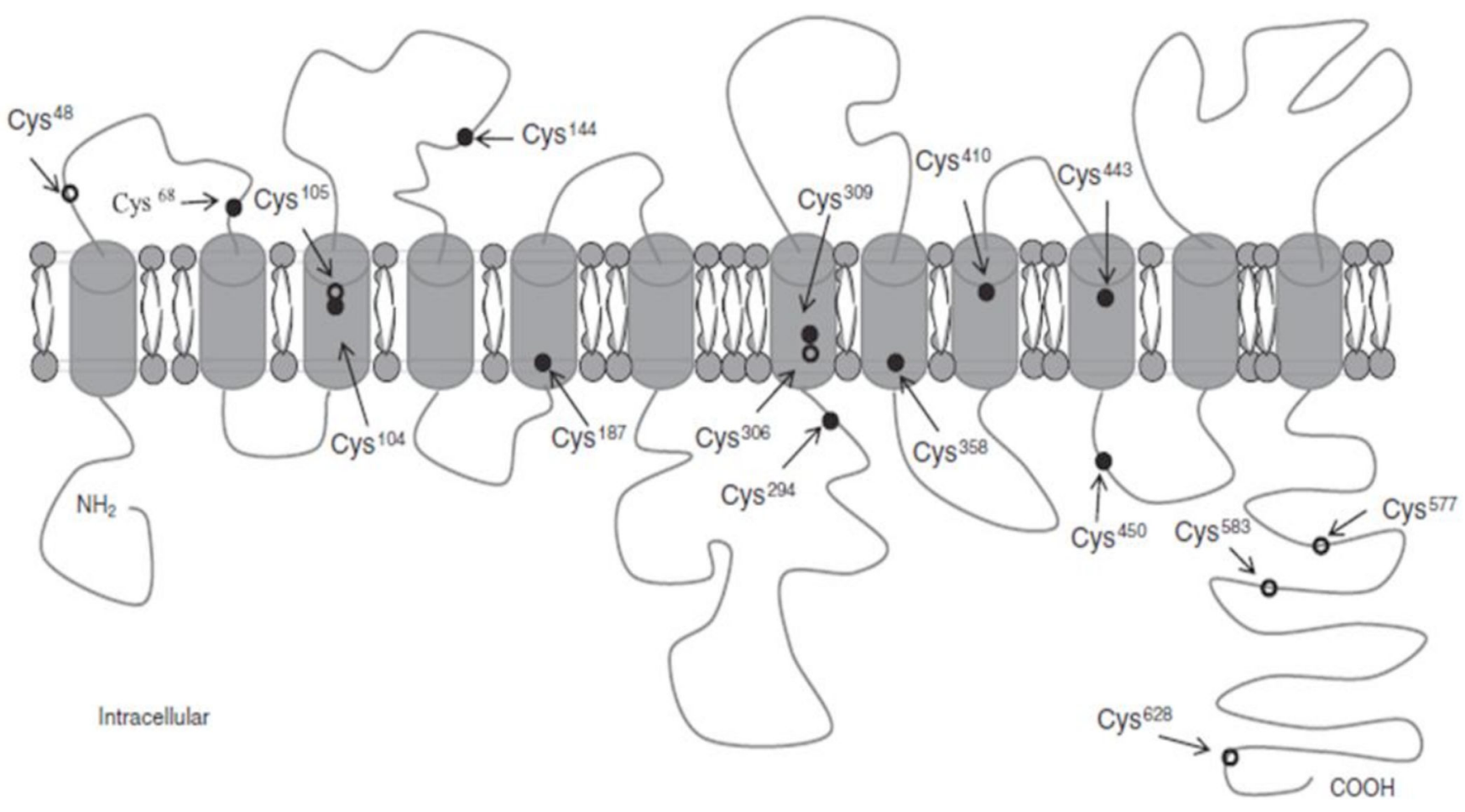

Fig. (3).

Predicted membrane topology of hSMVT and location of the conserved cysteine residues.

Filled circles depict the location of conserved cysteine residue whereas empty circles represent position of non-conserved cysteine residues. Reproduced with permission from Ref [33].

Curr Drug Targets. Author manuscript; available in PMC 2015 April 22. 

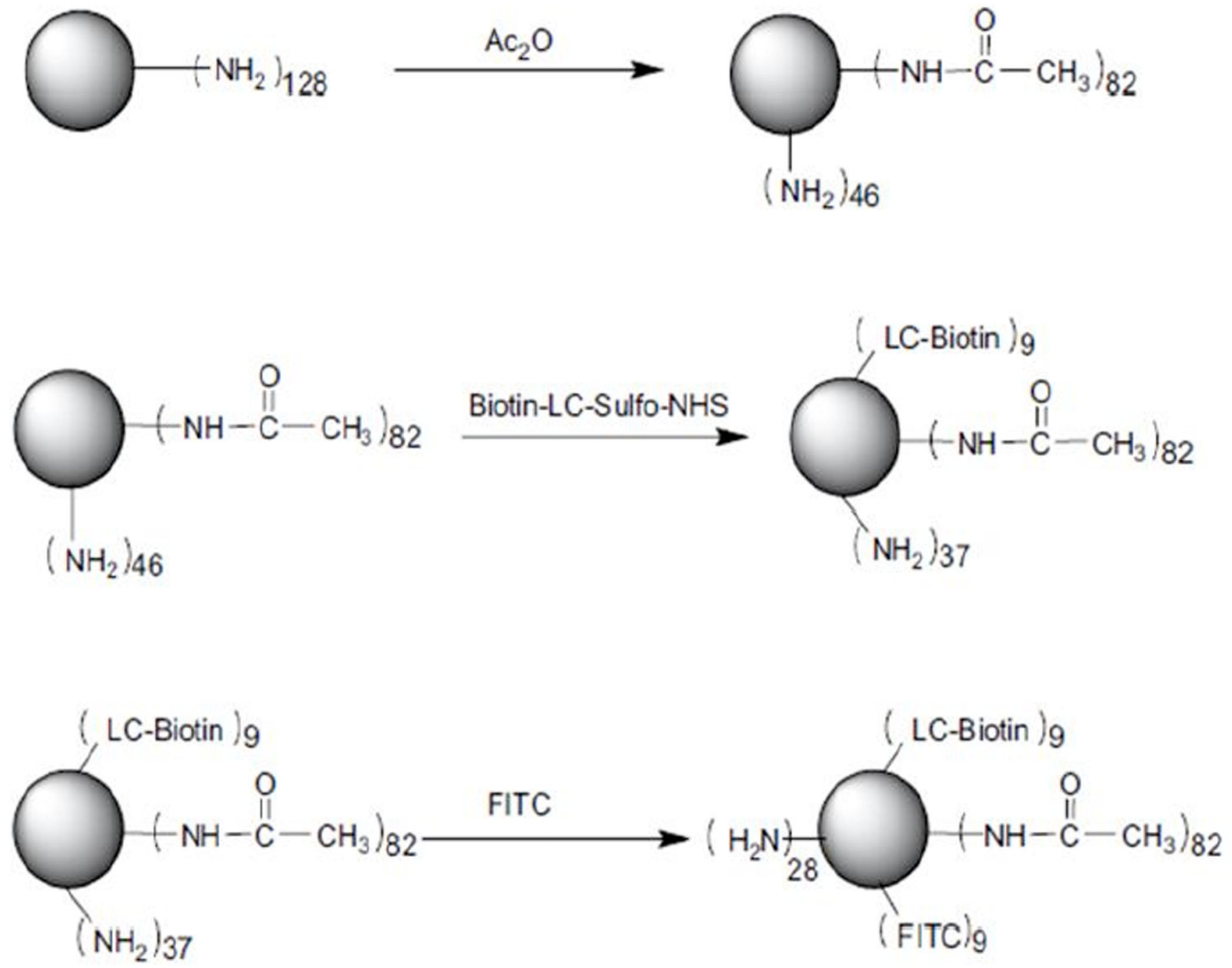

Fig. (4).

Schematic representation of the reactions involved in the synthesis of multi-functional PAMAM dendrimers for cancer cell targeting and imaging. Reproduced with permission from Ref. [63]. 
A

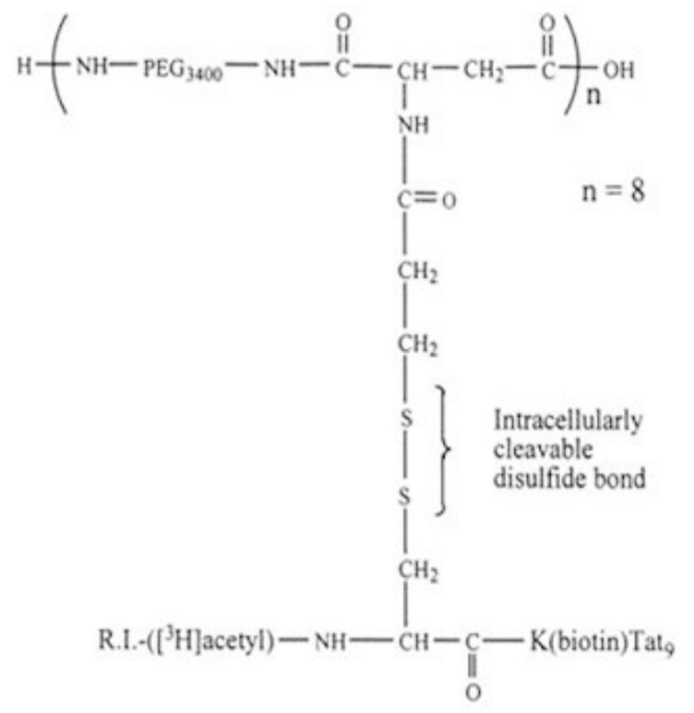

B

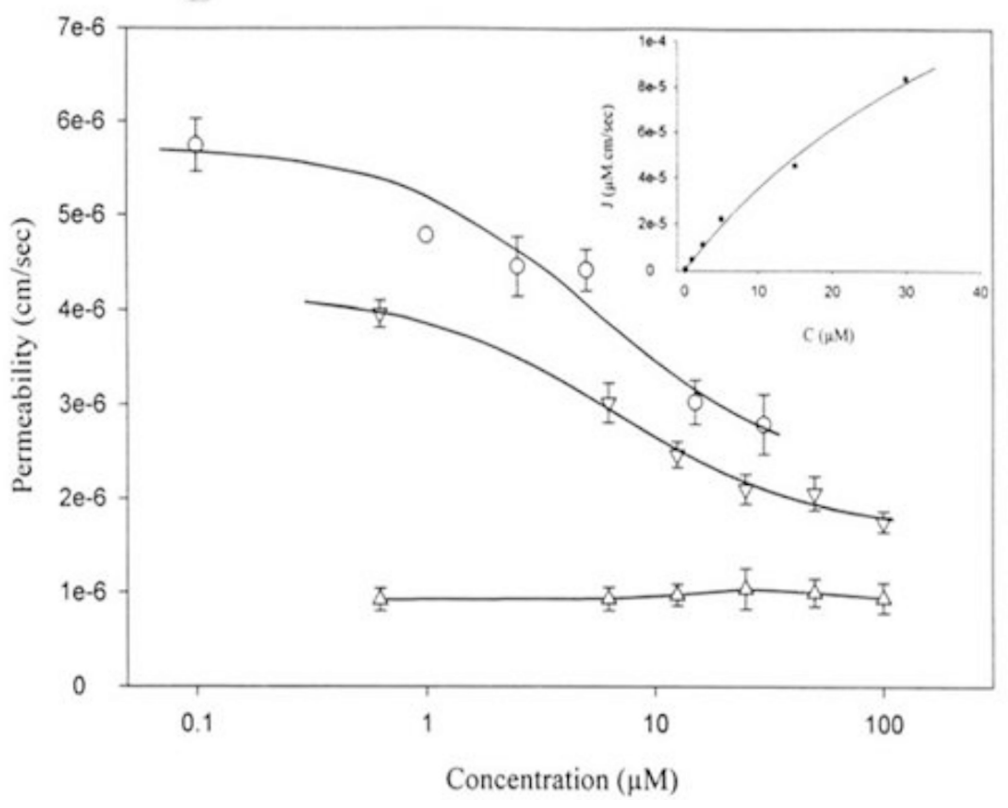

Fig. (5).

A) Structure of the PEG:(R.I-Cys-K(biotin)-Tat9) ${ }_{8}$ conjugate. B) Absorptive transport of biotin-PEG-3400 ( $\square$ ), PEG-3350 $(\triangle)$, and PEG:(R.I-Cys-K(biotin)-Tat9)8 $(\bigcirc)$ across Caco-2 cell monolayers. Reproduced with permission from Ref. [66]. 
A<smiles>Nc1nc2c(ncn2COC(CO)COC(=O)CCCCC2SCC3NC(=O)NC32)c(=O)[nH]1</smiles>

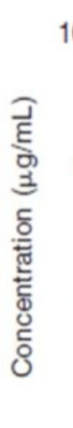

B

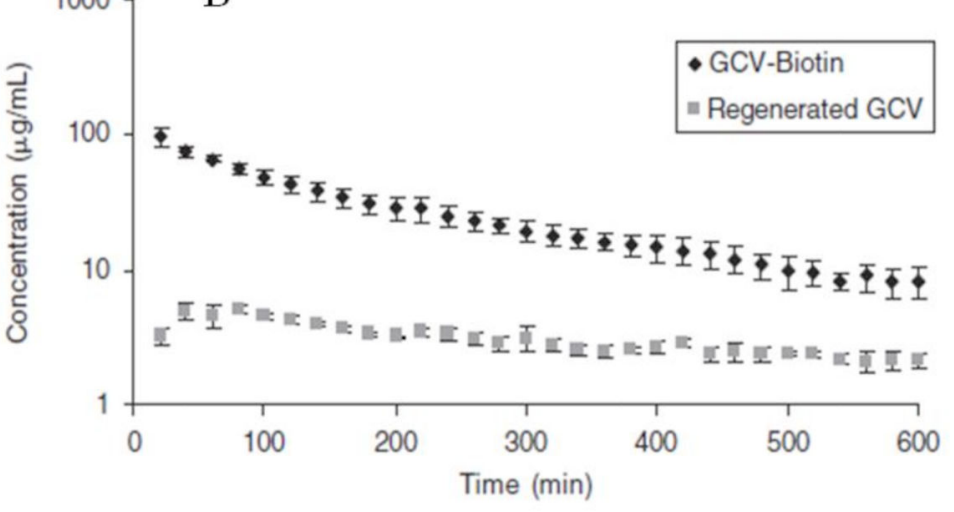

Fig. (6).

A) Structure of Biotin-GCV. B) Vitreous concentration-time profiles of Biotin-GCV and regenerated GCV. Reproduced with permission from Ref. [21]. 
Table 1

Summary of Tissue Distribution and Kinetic Parameters of SMVT Uptake Process (NR represents Not Reported)

\begin{tabular}{|c|c|c|c|}
\hline Species & Cells/Tissue & Kinetic parameters & Reference \\
\hline Bovine & Brain microvessel endothelial cells (BMEC) & $\begin{array}{c}\mathrm{Km}-49.1 \mu \mathrm{M} \\
\text { Vmax }-313.2 \text { pmoles/mg protein/min }\end{array}$ & [35] \\
\hline Canine & Kidney cells transfected with human $m d r 1$ gene (MDCK-MDR1) & $\begin{array}{c}\mathrm{Km}-13 \mu \mathrm{M} \\
\text { Vmax }-21.5 \text { pmoles } / \mathrm{mg} \text { protein/min }\end{array}$ & [43] \\
\hline Human & Colonic epithelial cells (NCM460) & $\begin{array}{c}\mathrm{Km}-19.7 \mu \mathrm{M} \\
\text { Vmax }-38.8 \mathrm{pmoles} / \mathrm{mg} \text { protein/3min }\end{array}$ & [36] \\
\hline Human & Intestinal brush border membrane (BBM) & $\begin{array}{c}\mathrm{Km}-5.26 \mu \mathrm{M} \\
\text { Vmax }-13.47 \mathrm{pmoles} / \mathrm{mg} \text { protein } / 20 \mathrm{sec}\end{array}$ & [56] \\
\hline Human & Kidney cortex brush border membrane & $\begin{array}{c}\mathrm{Km}-31 \mu \mathrm{M} \\
\text { Vmax }-82 \mathrm{nmoles} / \mathrm{mg} \text { protein/30 sec }\end{array}$ & [58] \\
\hline Human & Placental brush border membrane & $\begin{array}{c}\mathrm{Km}-21 \mu \mathrm{M} \\
\mathrm{Vmax}-4.5 \mathrm{nmoles} / \mathrm{mg} \text { protein/min }\end{array}$ & [34] \\
\hline Human & Proximal tubular epithelial cells (HK-2) & $\begin{array}{c}\mathrm{Km}-12.16 \mu \mathrm{M} \\
\text { Vmax }-14.4 \mathrm{pmoles} / \mathrm{mg} \text { protein/7 min }\end{array}$ & [57] \\
\hline Human & Retinal pigmented epithelial cells (ARPE-19) & $\begin{array}{c}\mathrm{Km}-138.25 \mu \mathrm{M} \\
\text { Vmax }-38.85 \text { pmoles/mg protein/min }\end{array}$ & [21] \\
\hline Human & Retinoblastoma cells (Y-79) & $\begin{array}{c}\mathrm{Km}-8.53 \mu \mathrm{M} \\
\mathrm{Vmax}-14.12 \mathrm{pmoles} / \mathrm{mg} \text { protein/min }\end{array}$ & [49] \\
\hline Human & Placental choriocarcinoma cells (JAR) & $\mathrm{NR}$ & [27] \\
\hline Human & Liver basolateral membrane vesicles & $\begin{array}{c}\mathrm{Km}-1.22 \mu \mathrm{M} \\
\text { Vmax }-4.76 \mathrm{pmoles} / \mathrm{mg} \text { protein/10 sec }\end{array}$ & [72] \\
\hline Human & Intestinal cells (Caco-2) & $\begin{array}{c}\mathrm{Km}-9.5 \mu \mathrm{M} \\
\text { Vmax - } 520 \text { pmoles/mg protein/min }\end{array}$ & [73] \\
\hline Rabbit & Intestine & $\mathrm{NR}$ & [26] \\
\hline Rabbit & Corneal epithelial cells (rPCEC) & $\begin{array}{c}\mathrm{Km}-32.52 \mu \mathrm{M} \\
\mathrm{Vmax}-10.43 \mathrm{pmoles} / \mathrm{mg} \text { protein/min }\end{array}$ & {$[50]$} \\
\hline Rat & Retinal capillary endothelial cells (TR-iBRB2) & $\begin{array}{c}\mathrm{Km}-146 \mu \mathrm{M} \\
\mathrm{Vmax}-0.223 \mathrm{nmoles} / \mathrm{mg} \text { protein } / \mathrm{min}\end{array}$ & [59] \\
\hline
\end{tabular}

